\title{
Design as co-evolution of problem, solution, and audience
}

\author{
Per L. Halstrøm \& Per Galle², \\ 'Copenhagen School of Design \& Technology; The Royal Danish Academy of Fine Arts, School of \\ Design. ${ }^{2}$ The Royal Danish Academy of Fine Arts, School of Design.
}

\begin{abstract}
The meaning of 'design' can be captured in a general way by a good definition, but even the best definition cannot provide an understanding sufficiently deep to guide the professional designer or the student of design in the intricate deliberations of doing design in practice. Therefore we explore design beyond the level of definitions, reviewing canonical theories about design as a professional enterprise. We find that the well-established theoretical notion of 'co-evolution' of problem and solution in design has its merits in regard to understanding design deliberations; but also that existing theories leave the practitioner at a loss for guidance in some respects. To remedy this situation, we propose the notion of 'triple co-evolution' that also involves the 'audience' of a designed artefact. Furthermore, we conjecture that the study of so-called 'constitutive rhetoric' offers valuable conceptual resources for conceiving of design in terms of such triple co-evolution. For example, many design products may be thought of as offering an audience a subject position' that hint at whom they should become. In support of the case we make for thinking in terms of constitutive rhetoric in design, we present a small sample of design cases, arguably showing signs of triple co-evolution and understandable in terms of 'audience constitution'.
\end{abstract}

\section{Keywords:}

audience constitution, constitutive rhetoric, design definition, design theory, wicked problems.

\section{INTRODUCTION}

Getting to know design - the overall subject of this paper - is comparable to getting to know a person. As we all know, there are at least three levels of knowing a person, ranging from the superficial to the intimate: (1) The postman, who is to deliver a parcel to the person in question, needs to know only the name and the address. (2) If the person has been reported missing, for example, the police will collect information from acquaintances and relatives in order to issue a description that, as far as possible, applies to this and only to this person, thereby enabling anyone to recognize him or her. (3) If you are to make friends with the person, however, it goes without saying that you should know the name and address of, and be able to recognize, that person; but the crucial thing is to know by acquaintance and experience what he or she is like. When it comes to knowing kinds of human action, such as design, there are three analogous levels at which we can know it:

At the 'name \& address' level (1), the subject of this paper is design, as practiced by professional designers and taught at academic institutions, such as universities and schools of design.

At the level of 'description for recognition' (2), we should define what we mean by the name 'design'. A good definition is basically a precise description of something in terms of characteristic features (much like the police description of a missing person), which enables us to recognize whatever was described, when we encounter it. A definition suitable for our current purposes should enable us to recognize the kind of action we call 'design'. Many definitions of 'design' have been offered in the theoretical literature; some of them rather too detailed and technical to discuss here (e.g., Bamford, 1990, p. 234; Houkes \& Vermaas, 2010, ch. 2), others much shorter and easier to memorize. An often-cited definition of the latter kind is Herbert Simon's: 'Everyone designs who devises courses of action aiming at changing existing situations into preferred ones' (Simon, 1996 [1969], p. 111). While it certainly captures 
something characteristic of design - the element of planning, which is also present in the complex definitions just cited - Simon's definition, if taken at face value, is much too inclusive. For example, if half asleep you lie in bed and contemplate rolling over to your left side, because lying on the back no longer feels good, that would be an instance of 'design' so defined! More aptly, 'design' can be defined as (the act of) 'creatively proposing an idea, so as to enable yourself or others to make an artefact according to the idea' (Galle, 2011, p. 93). Again planning is a central component of the concept. In much the same spirit, but even more succinctly, we might define 'design' as the art of conceiving and planning artefacts. The italicized phrase stems from Buchanan (1995, p. 26, emphasis added), except that he used 'products' instead of 'artefacts'. But 'products' again is too inclusive a term, if taken to mean anything resulting from a process of production; e.g. sawdust and noise would be among the 'products' of the production of wooden furniture. However, the use of 'artefact' in the latter two definitions seems appropriate for the purpose, if we take 'artefact' to mean 'an object that has been intentionally made or produced for a certain purpose' (Hilpinen, 2011 [1999]). Note that artefacts need not be restricted to material objects, but may (fully in accordance with Hilpinen's theory) include intangible entities as well, such as services, interfaces, organizations, and software (as advocated by Buchanan, 1998, 2001, 2004; Krippendorff, 2007).

So far, we have merely delimited our overall subject: getting to know design. What we aim at specifically, however, is to convey more detailed (and perhaps less commonplace) insights about the nature of design, at the level of 'acquaintance and experience' (3) - though without pretending thereby to offer a degree of familiarity with the subject analogous to what, in the human case, makes up a deep friendship. For the reader to achieve that, considerable first-hand experience will be indispensable.

In section 2 we briefly review some well-known general theories about design, and argue that viewing design as a rhetorical activity of persuasion, as Buchanan has proposed, is a fruitful approach to understanding its nature. However, we shall go beyond the notion of design as persuasion, and draw attention to what we believe is an important analogy between design and what is known as constitutive rhetoric.
To back up empirically our claim that design, too, may constitute an audience, we present a small sample of cases in section 3. These will illustrate a diversity of situations, some of which involve audience constitution.

Finally, in section 4, we sum up the outcome of our analyses, and outline perspectives for further work.

\section{THEORETICAL APPROACHES TO THE INTRICACIES OF DESIGN}

While a carefully worded definition may be useful as a point of departure for understanding the concept of design, it hardly ever does justice to the complex nature of actual design processes. But theorists have managed nevertheless to conceptualize and highlight the intricacies of design, and some theories may be instrumental to the practicing designer in coping with such intricacies.

\subsection{From 'wicked problems' to 'a rhetorical art of communication and persuasion'}

In our discussion of definitions, we emphasized planning as essential to design; and indeed Rittel and Webber long ago saw design problems as members of a family of difficult planning problems. For this family they coined the expression 'wicked problems' (Rittel, 1972; Rittel \& Webber, 1984 [1973]). By now the term is well established in the vocabulary of design theory. As opposed to what Rittel \& Webber called 'tame' problems, the 'wicked' problems are characterized by not being amenable to systematic methods; nor do 'wicked' problems have any clearly defined set of satisfactory solutions, so the decision to stop working on such a problem may be somewhat arbitrary. This openendedness, among other daunting characteristics, is what allegedly makes them 'wicked'.

In a similar vein, and to much acclaim and longstanding recognition, Schön (1983) drew attention to the remarkable ability of professionals to negotiate the intricacies of design and similar open-ended problems, by simple devices of 'experience, trial and error, intuition and muddling through' ( $\mathrm{p} 43$ ). In stark contrast, that is, to the systematic and computational methods very much in vogue among design theorists at the time.

Apart from narrowly technical cases (such as, say, design of integrated circuits, or the optimization of load-bearing structures), non-trivial design problems have remained rather immune to computerization and systematic solution. This, it would appear, is due to their 'wicked' tendency 
(vividly described already by Rittel \& Webber) to become fully comprehensible only to the extent one has already solved them! In other words, design problems and design solutions stand in a chicken-and-egg relation of mutual dependency, and therefore in practice tend to evolve in parallel. Numerous studies of such co-evolution of problem and solution have been reported in the literature (e.g. by Archer, 1979; Cross, 2006, p. 80; Dorst \& Cross, 2001; Harfield, 2007; Schön, 1983, p. 100). But how can theorists explain the fact that designers manage to overcome the inherent open-endedness of 'wicked' design problems by co-evolution?

Harfield, for instance (considering co-evolution particularly in architectural design, but assuming other kinds of design may be similar) draws a distinction between 'the problem-as-given' and 'the problem-as-design-goal' or, as he also puts it, the problem as 'taken' (2007, p. 169). In making a transition from the problem as given to the problem as taken, designers will more or less deliberately, but inevitably, generate a set of goals for their design process: namely, as he concludes, by 'imposing upon the problem-as-given their views, positions and preferences', thereby 'limiting the solution possibilities available to them' ( $p 172$, his italics).

Quite consistently with this, but conceiving of the matter in different terms, Buchanan (1995) maintains that unlike science, design is not about discovery, but about invention. Designers deal with no fixed and given subject matter, but with 'matters of choice'; ' with possible worlds and with opinions about what the parts and the whole of the human environment should be' (p. 25). Therefore, Buchanan suggests, the design process (as opposed to the history of design, concerned as it is with existing artefacts and their designers) should be thought of as 'a rhetorical art of communication and persuasion' (p. 27; emphasis added). This idea nicely complements the definition of 'design' as 'the art of conceiving and planning artefacts' (section 1 above).

As encouraging and insightful as Schön's and Harfield's accounts of (professional) design capabilities may be, they have little or nothing to offer by way of practical guidance to inexperienced designers or students of design struggling to cope with 'wicked' problems. Being aware of the value of experience in trial-and-error, and being able to distinguish problems as taken from problems as given, is undeniably important. Yet it seems to us that Buchanan's notion of design as a rhetorical art may hold greater potential for practical support and fruitful theory development for such support. For it points the designer towards explicit rational deliberation, rather than (to put it perhaps too bluntly) merely telling him or her to 'muddle through' and not to take problems at face value.

Expressing rational deliberation convincingly is not to forsake the use of one's intuition in the creative process. On the contrary, finding and giving good reasons for one's decisions may stimulate creativity, and help bringing it to fruition. Furthermore, in the designer's relation to clients, customers, and other stakeholders, competence in rational deliberation is valuable. This is why we find it worthwhile to explore design from the vantage point of rhetoric.

Admittedly, however, rhetoric has been studied in relation to design for various other reasons and purposes than those suggested by Buchanan and by ourselves. But attempting a full review of the intersection between rhetoric and design here would take us too far afield. The interested reader may wish to consult (Joost \& Scheuermann, 2008) for a comprehensive collection of papers. Another branch of design research worth noticing in the present context is that of 'emotional design', which has attracted considerable interest in recent years. Some of the ideas emerging under this label would seem to have a certain affinity to design-relevant notions of rhetoric (pathos, for example). So quite conceivably, some day design research may be in a position to explore and exploit similarities or analogies between its two branches of 'design as rhetoric' and 'emotional design'. But for now, and for our present purposes, suffice it to acknowledge emotional design as a potentially important field of 'related work'. For a broad accessible introduction, see (Norman, 2004); for examples of more recent treatments of special aspects of emotional design, see (Desmet \& Pohlmeyer, 2013; Fokkinga \& Desmet, 2013).

\subsection{Creative design as triple co-evolution}

In keeping with his notion of design as a rhetorical art, Buchanan once suggested that 'the designer, instead of simply making an object or thing, is actually creating a persuasive argument that comes to life whenever a user considers or uses a product as a means to some end' (1989, p. 95). Buchanan seems to take it for granted that if only the argument inherent in an artefact persuades its users, then the designer has succeeded. This may be so in cases where a well-defined group of users - the 'audience' of the artefact - is available; but that is not necessarily the case. 
Trying to determine the audience of a designed artefact in advance, simply by asking people what they want, is not always a viable approach. For, as Verganti shows in an important book (2009), people do not necessarily know what they want. Introducing a distinction between 'radical technological innovation' (p. 3) and 'radical innovation of meaning', alias 'design-driven innovation' (pp. 4-5), he contends that the potential of the latter has been neglected. To substantiate this claim, Verganti offers examples of designdriven innovation, all of which led to highly popular artefacts (including the Nintendo Wii, the Fiat Panda, and the Swatch watches). Despite being imbued with unexpected new meanings, these artefacts were embraced by users who had no idea in advance that they wanted them. - The moral of the story being that (except in cases of so-called 'incremental innovation' of limited novelty) market research is unlikely to predict the reception of a proposed design solution.

As important as this insight is to designers, and to business managers, Verganti leaves us with an unresolved problem. Obviously, the mere novelty of a creatively designed artefact is no guarantee that it will find an audience willing to use it: how, then, are creative designers who entertain an idea for a radically novel artefact, to evaluate its appeal to potential users?

We shall venture to suggest that a key to this problem lies in expanding Buchanan's conception of design as 'a rhetorical art of communication and persuasion'. What is needed, it seems, is to acknowledge that the audience is no more given in advance than the problem or the solution; that indeed creative design must proceed by a triple coevolution of problem, solution, and audience.

\subsection{Constitutive rhetoric: a conceptual tool for designers?}

In ancient Greece the audience would be a group of people gathered in the agora, listening to a speaker. That is how audiences used to be perceived in classical rhetoric: 'Aristotle and Cicero consider audiences purely as something given' (Burke, 1969, p. 64). However, contemporary communication via mass media does not face such a well-defined audience. It is best understood, therefore, under the assumption that it is not only about convincing an audience, but also in so doing, constituting that very audience. Audience constitution is a central idea of a modern branch of rhetoric known as constitutive rhetoric. Since audience constitution is precisely what makes the difference between the well-known concept of co-evolution in design, and the triple co-evolution for which we made a case above, it is hardly too far-fetched to conjecture, as we do, that constitutive rhetoric might inform the discipline of design in new and useful ways. Let us therefore briefly review the development of constitutive rhetoric, and then consider its potential for design.

Burke (1969) initiated a major development in rhetoric when he argued that identification plays a key role in any argumentative activity; without it, hardly any persuasion takes place: 'You persuade a man only insofar as you can talk his language by speech, gesture, tonality, order, image, attitude, idea, identifying your ways with his' (p. 55). Thus persuasion was no longer seen as merely depending on written or spoken words. Gestures, sartorial style, or works of art can be persuasive by creating identification (Foss, Foss, \& Trapp, 1991, p. 176). According to Foss et al, Burke's theory highlights the role of the audience in argumentation: The communicator might take any pains to make an audience identify with him or her, but whether or not that happens, is for the audience to decide.

Black offered a psychological explanation of why identification has come to play such an important role:

The quest for identity is the modern pilgrimage. And we look to one another for hints as to whom we should become. Perhaps these reflections do not apply to everyone, but they do apply to the persuasible, and that makes them germane to rhetoric. (Black, 1970, p. 113.)

Building on Burke's theory, Charland stated that 'neither (1) the ontological status of those in the audience before their identification [is clear], nor (2) the ontological status of the persona, and the nature of identifying with it' (1987, p. 137). In other words: (1) The audience is not given in advance, but is constructed by discourse. (2) Nor is it obvious with whom the audience is identifying, or believes to be identifying: is it the speaker, other members of the audience, or the persona as he or she is described in the discourse? Charland furthermore claimed that "we cannot accept the "givenness" of "audience," "person," or "subject," but must consider their very textuality, their very constitution in rhetoric' (p. 137), thereby introducing the constitutive perspective.

For Charland, the act of addressing someone is rhetorical; it works not by the use of arguments but by the use of identification. Subjects are influenced by the subject position they are given within a discourse: 
The process by which an audience member enters into a new subject position is therefore not one of persuasion. It is akin to one of conversion that ultimately results in an act of recognition of the "rightness" of a discourse and of one's identity with its reconfigured subject position (p. 142).

For example, if one is addressed as a Dane and accepts that subject position, then one is already persuaded to be in favour of a set of values inherent in being Danish and to differ from someone who is not Danish. There is an implicit narrative to which one subscribes and by which one is influenced when assuming a particular subject position. It is worth noting, though, that this subject position is less determinate than it might seem. As Charland recognizes, we may enter many and even contradictory subject positions.

Charland's notion of the constitution of an audience through identification is closely related to Black's theory about the 'second persona': an implied auditor inherent in the discourse. Black introduces the term to highlight the distinction between the actual audience addressed by a speech and the implied audience as it appears in discourse (Black, 1970).

The notion of design being able to assemble an otherwise non-existent audience is not entirely new to design studies. It has been explored by DiSalvo in his writings on political design (2009). Political design should not be confused with design for politics, which merely seeks to design 'structures and mechanisms that enable governing' (DiSalvo, 2012 , p. 8) Political design, on the other hand, seeks to question those same structures and mechanisms. Thus political design is similar in nature to Dunne \& Raby's 'critical design' (Dunne, 1999, p. 117).

Where our perspective differs from that of DiSalvo is in our focus of attention. DiSalvo uses Dewey's notions of publics to describe how design can bring an actual group of people together 'trough and around an issue' (DiSalvo, 2009, p. 51). While this makes us aware of design's ability to prompt a debate about an issue, it leaves us none the wiser on the ways artefacts can bring audiences into being. Our focus, on the other hand, is on describing the ways an artefact may create and influence an audience by giving it an identity and a subject position.

There is a fundamental difference between Black's and Dewey's perspectives. Whereas Dewey describes the construction of actual audiences, Black considers how an audience appears in discourse. Whether there is an actual audience or not is irrelevant within his framework. Proposing the term 'second persona' to denote the auditor implied by a discourse, he seeks to reveal the ideology inherent in that discourse. The implied auditor might or might not have anything to do with an actual audience (Black, 1970).

We believe this way of analysing discourse is useful to designers for revealing what might be the intended effects and inherent ideology of a proposed artefact. But whereas DiSalvo looks at design's ability to question structures in our society, we aim to look at design's ways of structuring our ways of living, and to reveal some of the means by which this is done. For this purpose we need to move further into the domain of rhetoric than to introduce the second persona as a means to analyse inherent ideologies of artefacts. Though conceptually useful for analysis, Black's second persona seems applicable to any artefact if one assumes that an artefact is capable of implying an audience, and this assumption seems almost selfevident. What we claim is that some artefacts, but not all, constitute their audience in ways that can be fruitfully described in the language of constitutive rhetoric.

Scholars of rhetoric have used the term 'constitutive rhetoric' as a vehicle for critical analysis of political discourse, where speakers claim particular rights on behalf of an audience they constitute for that very purpose. The citizens of Quebec being addressed 'Peuple Québécois' is a case in point that was analysed by Charland (1987). Pretending to speak on behalf of 'the people' in order to attain political goals, could be a rather manipulative enterprise. In general, addressing people as a unit can be something of a semantic fraud, if those people would not exist as a unit without the discourse addressing them as such (ibid. p. 136). Hence 'constitutive rhetoric' carries a certain negative connotation; but it has more straightforward and innocuous applications as well. Stein (2002), for example, analysed a commercial campaign by Apple in 1984, which served to constitute the audience whose desires the Apple products were designed to fulfil.

We, for our part, propose to introduce constitutive rhetoric to the design and design research community, as a conceptual tool for analysing, understanding, and eventually supporting design deliberation. We do not thereby intend to judge whether or not particular design projects are immoral or semantically fraudulent. Our long-term 
goal is to alleviate the problem for the creative designer that we outlined in section 2.2 , by reconceptualizing the design process in a way that the existing body of design theory does not enable.

In the light of what we have said about 'design as triple co-evolution' it seems to us, at least prima facie, that some of the conceptual tools afforded by constitutive rhetoric may turn out to be useful in a context of design discourse as well. For example, a creative designer entertaining a radically novel idea, might find it useful to keep in mind that no audience is readily at hand; but only an imagined audience to whom the designer communicates. Furthermore, that such intangible 'auditors' will only be brought into reality by an act of 'conversion' if enough people undergo an 'identification', and agree to become audience for the design, thereby subscribing to its implied narrative.

Design, at least in such cases as the ones we shall analyse in Section 3, can be described as 'the art of planning and conceiving artefacts' (compare Section 1) that offer their users a subject position, and in doing so assist them on their 'modern pilgrimage' as they 'look to one another for hints as to whom [they] should become' (Black, 1970, p. 113).

Admittedly, much clarification and conceptual development is called for, in order to convert these vague inklings into operational design theory of practical value. This is beyond the scope of the present paper, but what we can do, and will do below, is to consider a few design examples with these preliminary ideas in mind, to get an initial impression of their viability.

\section{EXAMPLES OF TRIPLE CO-EVOLUTION}

Before we proceed to describe our selection and analysis of design cases that (arguably) show signs of triple co-evolution, a caveat is in order: Co-evolution (whether twofold or triple) is a phenomenon that often occurs in design, and being familiar with it is of paramount importance to practicing designers, teachers, and students of design. But co-evolution is not a defining characteristic of design (as noted initially, even the best definition only goes some way towards a deep understanding of the concept). For co-evolution does not always occur in design - not even in all non-trivial cases. To bring home this point, the following example will do:

Design a packaging product to contain pills for pain relief in patients who suffer from severe arthritis of the hands, subject to the following constraints imposed by the manufacturer: The product must be airtight; users must not be required to twist or press the product; the cost must not exceed that of conventional packaging products. (Example originating from Mette Bak-Andersen, personal communication, June 2013.)

The example is non-trivial, because taken together the constraints do not admit of any obvious solution. (As pointed out by Bak-Andersen, well-known types of packaging such as pill bottles and blister cards are ruled out by the second constraint; because, ironically, they would cause the patients much of the pain that the pills were intended to relieve.) Yet co-evolution is unlikely. The problem is clearly stated, in terms of reasonable and non-negotiable conditions. The 'audience', too, is fixed: a particular group of patients with a problem that calls for a particular solution.

\subsection{Collection and analysis of design case information}

The sample of design examples presented in the following subsections was selected to illustrate triple co-evolution, seen in the light of constitutive rhetoric. Due to space and time constraints, the sample is limited to only three cases (all collected by the first author). So, whatever support the sample may lend to our conjecture about the potential of constitutive rhetoric for informing design deliberation, it will derive from qualitative, rather than quantitative considerations. Yet to provide as much variety as practically possible, we picked two examples from the academic literature (Verganti, 2009), while the third is an MA degree project completed by a student at The Royal Danish Academy of Fine Arts, School of Design, in the Spring of 2013. As the degree project was given top marks by the examiners, we consider it a plausible example of professional design, albeit at a much smaller scale than the other two examples.

For the purposes of this paper, the selection of the degree project was made deliberately in search of signs of triple co-evolution. To avoid unduly influencing the informant, this was done without interaction with the student during her work on the project, or with the examiners prior to the exam. Information was gathered solely by attending the student's presentation to the examiners, and the ensuing dialogue; and by subsequently conducting semi-structured interviews with the student. However, we are part of the same institution as the student, and so all of us might inadvertently have been sharing the same modes of thought or intellectual traditions. Therefore we do not present the student's project as indisputable 
evidence in support of our theoretical viewpoints, but rather as an example well suited to illustrate them. We also include this example to show how audience constitution may be at work even within an educational setting devoid of the industrial complexity and financial constraints of the large commercial projects that we consider.

For different purposes of an on-going research project, from which the idea for the present paper emerged, a great many other student projects were investigated in a similar manner, including thirteen others at MA degree level. However, as in this paper we only use design cases for illustration of a theoretical conjecture, a systematic treatment of the entire empirical material cannot be attempted here.

What we can and will do, is to subject our examples to a predominantly hermeneutical reading (see, e.g., Leff, 1997), in the light of the constitutive rhetoric as presented above, in order to explore the potential relevance of such rhetoric for handling triple coevolution in practical design deliberation.

\subsection{The Wii console constituting an audience}

Let us return to the Nintendo Wii as our first example. (See Figure 1.) According to Verganti (2009, pp. 62-67), this artefact succeeded because it epitomized a 'radical change in meaning', rather than reproducing or slightly modifying the meaning of existing game console products.
The Nintendo Wii was released in 2006 when Sony's PlayStation and Microsoft's Xbox were leading brands in the computer game industry. Both Sony and Microsoft were aiming at improving technical performance of their consoles, but without changing their basic functionality and meaning. The Wii, on the other hand, introduced new functionality, allowing users to control a game with physical gestures as well as button-pressing. Hence, it also 'offered a radical change in meaning [...] from an immersion into a virtual world approachable only by niche experts into an active workout, in the real world, for everyone' (p. 63).

The point of this example, as we see it, is that there is a complex connection between problem, audience, and solution, which results from the malleable nature of these during the design process. The design problem is always a problem to someone. However, as long as this 'someone' is kept in a state of flux, so is the problem.

Whereas conventional game consoles solved a 'problem' for gaming enthusiasts, offering them entertainment, the Wii is still solving the problem of entertainment for gaming enthusiasts, but also solves a social problem for families, and a health problem of physical inactivity. Young males for instance, when immersed in conventional gaming, might be physically inactive and isolated from the rest of the family, to whom such gaming did not appeal. By contrast, the very act of gaming with

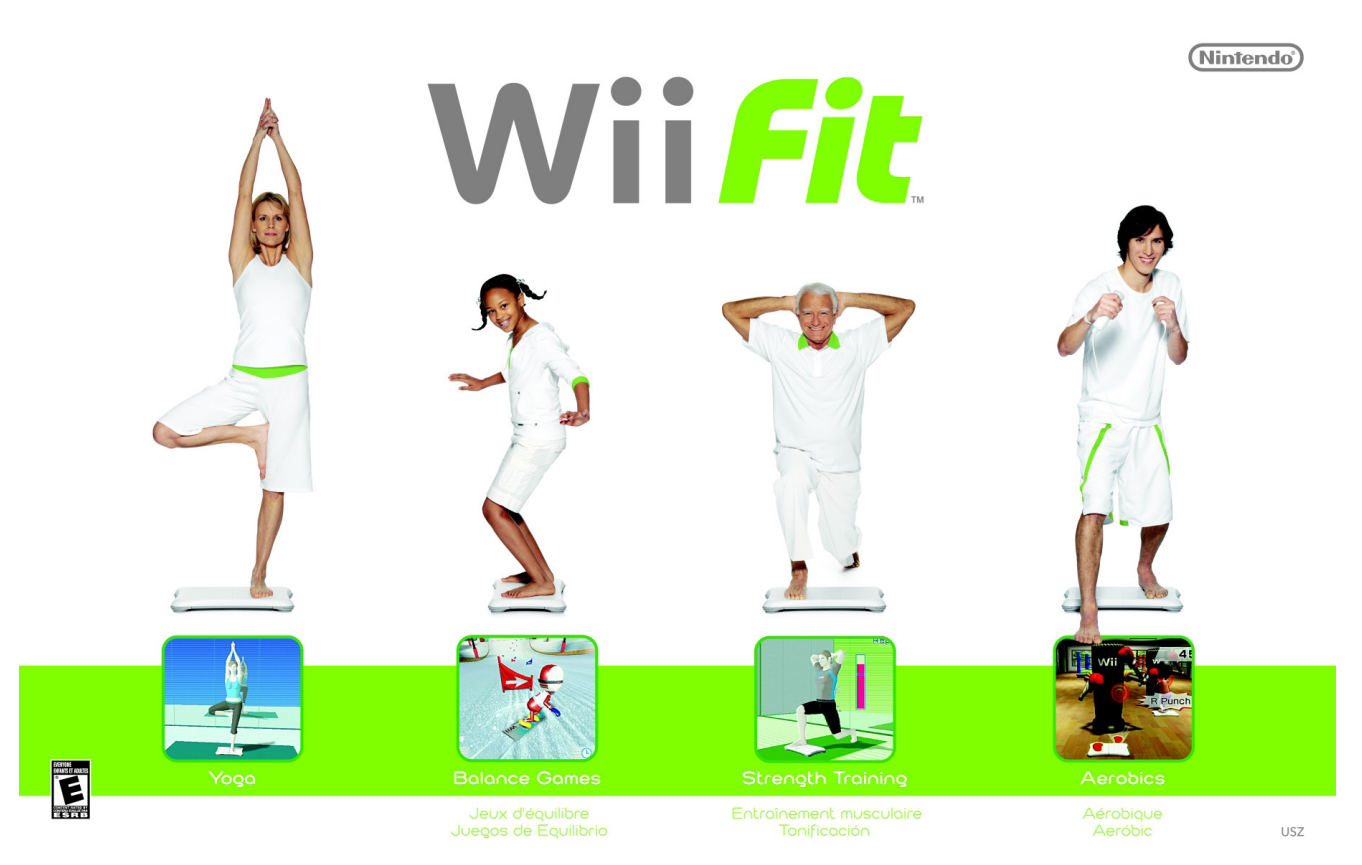

Figure 1. Wii Fit became one of the best-selling games of all time. Here shown with the Wii Balance Board peripheral.

Illustration: Nintendo 
the Wii is a physical activity inviting participation of several family members. Gaming is no longer a matter of entertainment only, but one of social interaction and physical play as well. This is not to say that gaming before the advent of the Wii could not be social. But, as argued by Jones \& Thiruvathukal (2012) in their thorough treatise of Wii, the social aspects were not emphasized by conventional consoles to the extent they were in the design of the Wii (p. 141). It used space in a different way since it shifted the attention to be as much in the physical world as on the screen.

As pointed out by Jesper Juul, this change was reflected in the pictures posted to Flickr: when searching for Gears of War 2 he primarily found pictures of in-game battles, whereas when searching for Wii Tennis the percentage of pictures of people playing in their living rooms was much higher (Juul, 2010, p. 117). Jones \& Thiruvathukal vividly describe the change by contrasting the cover image of David Sheff's book 'Game Over' (1993), in which a lone young male gamer sits staring into a TV set, as if hypnotized, with the many images from Nintendo ads 'showing ethnically and genderdiverse groups of happy people [...] playing and laughing together, moving around in player space' (Jones \& Thiruvathukal, 2012, p. 141).

In 2007, Nintendo released further motion-sensitive devices, including the 'Balance Board' that enables users to simulate Hula Hoop or skateboarding games. And this, as Verganti points out, 'shifted the meaning of the Wii even further [...] toward a tool for fitness and even physical therapy' (op. cit. p. 67). For example, for stroke victims undergoing such therapy, the Wii now solved the problem of avoiding boredom during the exercises, and to their therapists it solved the problem of motivating patients.

Thus in the case of the Wii, a single artefact embodies a variety of solutions to multiple problems, and thus manages the constitution of multiple audiences. To attain this, the 'problem' and the audience ('user') must have been thought of by the designers in fairly vague terms, or deliberately kept in a state of malleability. According to the company's press release in 2006 they deliberately wanted to 'break down that wall that separates game players from everybody else.' (quoted from Jones \& Thiruvathukal, 2012, p. 139). Obviously the designers could hardly have been thinking of an audience literally including mankind as a whole ('game players' and 'everybody else'), since this would be absurd as well as unhelpful. Yet it also seems highly implausible that the designers (in marked contrast to the pill-packaging example) could have been working from a design brief stipulating the audience(s) in precise terms such as these: (1) Young(ish) males who like immersion in videogames. (2) Parents who would like to play with their children but are not interested in videogames.

(3) People (elderly or physically impaired) who might prefer exercise at home to doing workouts in fitness centres. (4) Patients who find therapeutic exercises boring. (5) Therapists who want to motivate patients to do physical exercises. (6) Game developers who find it attractive to develop games for simple graphics processing. (As for item no. 6, Verganti explains that ' $[\mathrm{d}]$ evelopers could create new games much more quickly and cheaply. Experts estimated that the average cost of developing a game for the Wii was $\$ 5$ million, compared with $\$ 10$ million to $\$ 20$ million for PlayStation 3 and Xbox' ( $p$. 67).) Only in hindsight can such a description of the inhomogeneous audience of the Wii be put together.

The Wii can be understood as an artefact that constitutes an audience made up of disparate groups of people: All of these identify, for reasons of their own, with the Wii and the audience it implies. Audience members subscribe to the narrative inherent in the artefact. And they subscribe to the values they feel they share, in their capacity of belonging to the newly emerged community of Wii gamers. - In Charland's terms, the audience consists of those who convert and recognise the 'rightness' of the Wii and affirm their subject position as Wii gamers.

What Buchanan might call the argument of the product, includes something like this: People of different ages should have active fun together. Most people would subscribe to this, but that does not account for the success of the Wii. Since other artefacts might embody a similar argument without being equally successful, something else is at stake. Viewed from the vantage point of constitutive rhetoric, Wii users are not persuaded by the argument, but identify with the Wii gamer constituted by the product. Again this process, in our perspective, is far less one of persuasion than one of identification and conversion. This also explains why people might turn away from the product when they no longer find it desirable to identify. It is not that it no longer solves a problem that is relevant to them, nor that they no longer agree with its argument, but that they no longer wish to convert. 
There is some evidence that Nintendo might have been aware of the constitutive power of the Wii. For one thing, the name 'Wii' is pronounced like 'we'. This suggests a reference to the community of Wii gamers, as explained at Nintendo's own website (according to Carless, 2006). Likewise, the initial television campaign for the Wii emphasised the wordplay by having two actors say 'Wii (we) would like to play' while holding up a Wii remote (Jones \& Thiruvathukal, 2012, p. 140). Furthermore, the ads for the Wii were not featuring the games that people could play on the console, but were portraying the players. The product itself was not in focus: 'the ads turned the camera 180 degrees toward the people who were playing - typically representing many ages - as they moved and enjoyed themselves' (Verganti, 2009, p. 63).

At the same time, however, it could be argued that this campaign proves little about what Nintendo might have been aware of since constitutive rhetoric is used often in advertising as an instrument for winning people over. As we mentioned earlier, Stein has noted this about Apple ads. And if we look at companies' loyalty programs we easily detect various attempts to constitute an audience of people being not just someone deciding to buy a product but someone who identifies with the company and are willing to 'convert'. This is attempted by phrases such as: 'Ikea Family', Panera Bread's 'MyPanera' rewards, or Loews Hotels' 'You First Rewards'. Indeed, deliberate audience constitution has long been commonplace in advertising, so in that sense it is not novel. What we suggest, however, is that design professionals, too, might benefit from adopting deliberate audience constitution for purposes of their own, such as stimulating their quest for quality and creativity.

\subsection{The Swatch Watches providing a subject position}

Let us consider another example of what Verganti refers to as an act of radical innovation; this time involving a rather different kind of artefact. As we shall argue, the example illustrates how a designed artefact is able to provide a subject position for its audience to confirm.

When Swatch watches were introduced there had been two types of meanings conveyed by watches: Expensive Swiss watches were best understood as jewellery-like objects full of delicate machinery and materials manufactured to extreme levels of precision. On the other hand, cheap watches manufactured in Asia typically with digital displays were best understood as multi-purpose instruments with tools such as alarm clocks, games, timer, and calculator (Verganti, 2009, p. 71).

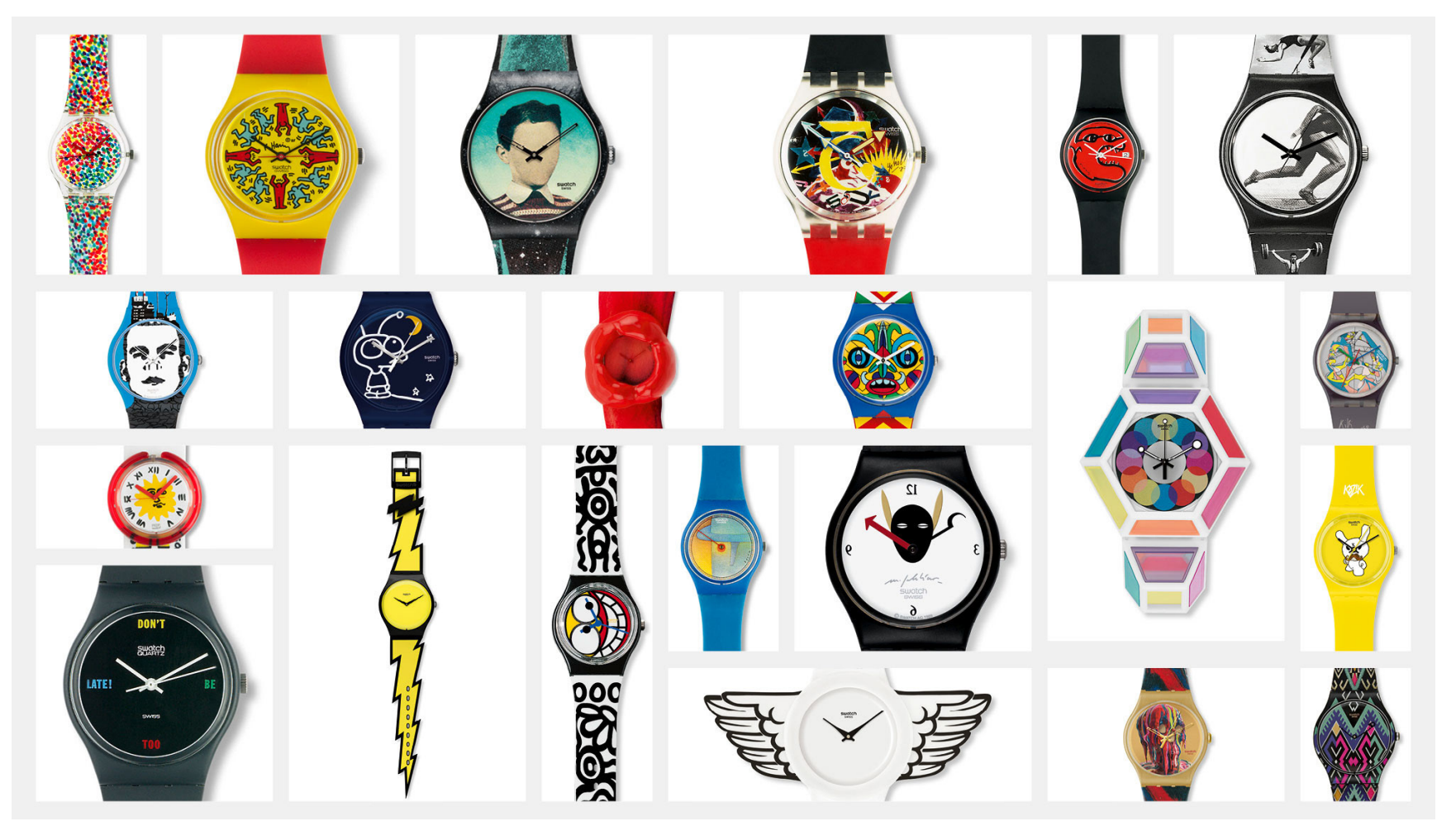

Figure 2. Swatch Art. A collection of Swatch watches decorated by artists. Source: www.swatch.com 
Swatch presented watches with an altogether different meaning: that a watch could look playful, be more of a fashion accessory, and express the joy of life. (See Figure 2.) It was a watch that was cheap enough for a lot of people to buy. Some even bought more than one, like ties. It came in many different colours, and various artists were invited to design their versions of the watch, as explained by Hayek, chairman and CEO of The Swatch Group (Verganti, 2009, p. 70 ). The problem that a watch basically is to solve is to tell the time (and, in the case of the Asian watches mentioned above, to solve some other problems too). The Swatch watches, however, would seem to offer a solution to a lifestyle problem; to satisfy a need for self-expression, more than anything else.

Once designers switch their attention from solving practical problems to solving such problems of self expression, successful design becomes first and foremost a matter of identification. What such a design product as a Swatch watch does, is to provide an opportunity for its audience to express themselves through the product. Although the watch still tells the time, its audience is persuaded, we submit, not so much by an inherent argument, as Buchanan would have it, as by an impulse to identify with the subject position offered by the product.

Presumably in many cases, we do not choose the artefacts we do because we believe that they will solve the problem they seem to be made to solve: a watch solving the problem telling the time, a bike or a car solving the problem of transportation, a dining table solving the problem of gathering friends or family around a meal, and so forth. We would suggest that in many such cases design's persuasive abilities are better explained if we talk about design as a creator of subject positions that an audience is willing to enter because they identify with it. A Swatch watch gives us an opportunity to confirm a subject position as an audience that expresses fashionable living and the joy of life.

But how is this to support design deliberation? We propose that understanding and analysing design in terms of these rhetorical concepts has the ability to inform and aid the designers' decision-making - in particular when it comes to design processes in which designers work with 'wicked problems' or problems that are malleable and solutions that are equally malleable. We do not attempt to reduce the complexity of these processes but to propose a description that might assist designers as they navigate within these malleable notions of problem, solution and audience. For example, the designer should consider questions such as these: Would there be an audience that might identify with this subject position that my design is creating? What audience am I implying by this form of solution that I am creating? The design process then becomes one of discovering ways to create a subject position for an audience to identify with.

For instance, in the design process that led to the Swatch watches, we imagine that the colours and other features were chosen so as to evoke a state of mind in an audience, in which people can see themselves as fashionable and sophisticated, expressing the joy of life. The choice of an analogue display, too, would help create this subject position, and make it attractive to identify with. The same goes for the choice of price range, the shape, the materials. The aim would have been to make potential customers see themselves in a certain light, and by that very act of imagination become an audience.

\subsection{A multi-purpose lamp}

For her MA degree project in design, completed at The Royal Danish Academy of Fine Arts, Kathrine Lønstad made a moveable lamp called On The Edge. It invites the user to move the lamp depending on what kind of lighting is needed. It can hang from the ceiling, or it can lie on a table or on the floor, resting on one of several differently oriented facets. It might light up the table as a pendant lamp on one occasion, and on another it could be pointed towards a wall or a corner to create an atmosphere in the room. (See Figure 3).

Kathrine Lønstad began work by asking herself, what if our everyday objects reflected the lives we live far more than they do? Through research in private homes she observed that domestic activities were often transcending what she called the regular 'zones' in the home. The living room for instance, could also serve as a home office. In her opinion, this called for more flexible objects that could be used in multiple ways.

Again, we submit, the resulting artefact could be understood as one that moulds its audience into being, rather than addresses an audience waiting for such a solution to satisfy their needs. The lamp suggests a more flexible way of domestic life. It hints about who the user is, or might become, thereby constituting an audience in favour of that way of living. However, audience members are not (or not exclusively) persuaded by the argument that Buchanan might say is inherent in the lamp. It is an object that seeks to evoke, and in so doing, to 


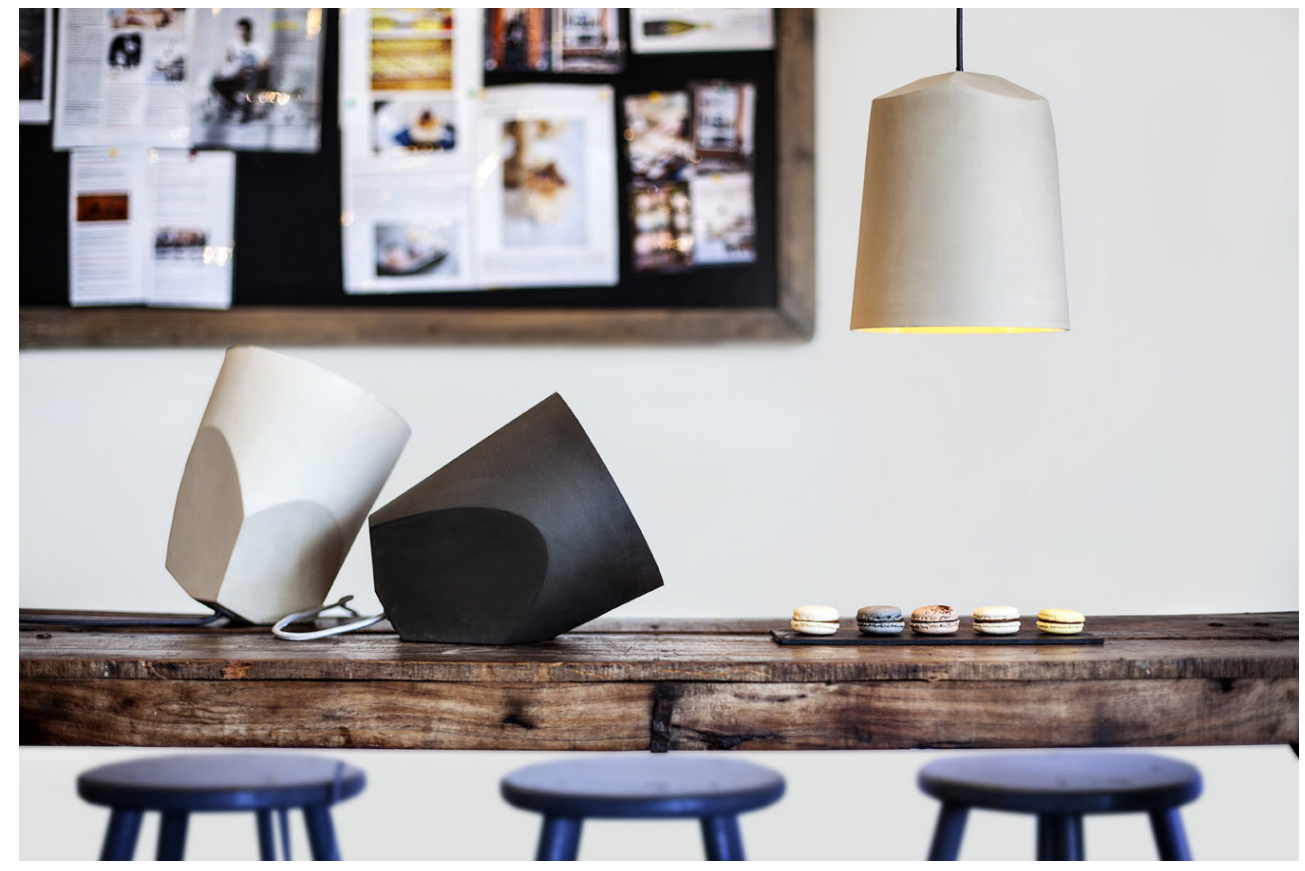

Figure 3. Movable multi-purpose lamp On The Edge. Design: Kathrine Lønstad.

Photo: Tudor Cioroiu. Reproduced by permission offer a subject position to identify with, at the same time as, and perhaps precisely in virtue of, being a practical tool that helps audience members live in a way they already appreciate. The success of $\mathrm{On}$ The Edge depends on its ability, by so appealing, to pick out in sufficient numbers an audience: namely, those and only those who subscribe to its inherent ideology, narrative, or values, and who therefore tend to confirm their subject position as audience for On The Edge.

Although perhaps manifest empirical evidence in support of such claims is hard to come by, we believe that interpreting the triple co-evolution of On The Edge in terms of constitutive rhetoric makes sense.

\section{CONCLUSION AND PERSPECTIVE}

We have explored the concept of design at the three levels set out in our opening paragraph. At the first level we merely restricted our scope of interest to design as practiced by professionals and taught to design students. At the second level, we settled for characterizing our subject matter as 'the art of conceiving and planning artefacts'; this phrase adequately captures the essence of more elaborate definitions of 'design' in the research literature. To understand design at the third level, beyond what definitions can offer, we reviewed, in section 2 , some canonical theories about the intricacies of deliberation involved in actually performing design. As a result, the notion of triple co-evolution (of problem, solution, and audience) emerged as a commendable extension of the well-known coevolution of problem and solution. This result we regard as fairly plausible, with the reservation that not all acts of design involve co-evolution (whether simple or triple). In addition, we conjectured that where existing design theory leaves the practicing designer at a loss for guidance, a study of design through the lens of constitutive rhetoric might lead to new understanding of theoretical and practical value, and we found some preliminary support for this in the small sample of cases presented in section 3 . Whether this conjecture will stand up to closer scrutiny, however, remains to be seen.

\section{ACKNOWLEDGEMENTS}

We are grateful to a number of people for supporting the work on this paper in various ways: Our colleague, Mette Bak-Andersen, of Copenhagen School of Design \& Technology, related to us the packaging-design example used in the introduction to section 3. Many design students allowed us to study their projects in preparation for our paper. In particular, designer Kathrine Lønstad kindly granted us permission to present and analyse her MA project as a case study. Last but not least, two anonymous reviewers offered helpful and constructively critical comments on an earlier version of the paper. 


\section{REFERENCES}

Archer, B. (1979). Whatever became of Design Methodology? Design Studies, 1(1), 17-18. http://dx.doi.org/10.1016/0142$\underline{694 X(79) 90023-1}$

Bamford, G. (1990). Design, science, and conceptual analysis. Architectural science and design in harmony. Joint ANZAScA/ADTRA Conference (pp. 229-238), Sydney, 10-12th July, 1990.

Black, E. (1970). The second persona. The Quarterly Journal of Speech, 56(2), 109-120.

Buchanan, R. (1989). Declaration by design: rhetoric, argument, and demonstration in design practice. In V. Margolin (Ed.), Design discourse. History. Theory. Criticism (pp. 91-109). Chicago: University of Chicago Press.

Buchanan, R. (1995). Rhetoric, humanism, and design. In R. Buchanan \& V. Margolin (Eds.), Discovering design. Explorations in design studies (pp. 23-66). Chicago: University of Chicago Press.

Buchanan, R. (1998). Branzi's dilemma: design in contemporary culture. Design Issues, 14(1), 3-20. http://dx.doi. org/10.2307/1511825

Buchanan, R. (2001). Design research and the new learning. Design Issues, 17(4), 3-23. http://dx.doi. org/10.1162/07479360152681056

Buchanan, R. (2004). Design as inquiry: the common, future and current ground of design. Paper presented at the DRS Futureground International Conference, Melbourne.

Burke, K. (1969). A rhetoric of motives. Berkeley: University of California Press.

Carless, S. (2006). Breaking: Nintendo Announces New Revolution Name - 'Wii'. Gamasutra. The art and business of making games. April 27th. Retrieved August 20, 2013, from http://www.gamasutra.com/php-bin/news index. php?story $=9075$

Charland, M. (1987). Constitutive rhetoric: the case of the Peuple Québécois. The Quarterly Journal of Speech, 73(2), 133-150.

Cross, N. (2006). Designerly Ways of Knowing. London: Springer.

Desmet, P. M. A., \& Pohlmeyer, A. E. (2013). Positive Design: An Introduction to Design for Subjective Well-Being. International Journal of Design, 7(3). Retrieved from http://www.ijdesign.org/ojs/index.php/IJDesign/article/ view/1666/595

DiSalvo, C. (2009). Design and the construction of publics. Design Issues, 25(1), 48-63.

DiSalvo, C. (2012). Adversarial Design. Cambridge, MA: MIT Press.

Dorst, K., \& Cross, N. (2001). Creativity in the design process: co-evolution of problem-solution. Design Studies, 22(5), 425-437. http://dx.doi.org/10.1016/S0142-694X(01)00009-6

Dunne, A. (1999). Hertzian tales: electronic products, aesthetic experience and critical design. London: Royal College of Art.

Fokkinga, S. F., \& Desmet, P. M. A. (2013). Ten ways to design for disgust, sadness, and other enjoyments: A design approach to enrich product experiences with negative emotions. International Journal of Design, 7(1), 19-36.
Foss, S. K., Foss, K. A., \& Trapp, R. (1991). Contemporary perspectives on rhetoric (2nd ed.). Prospect Heights, IL.: Waveland Press.

Galle, P. (2011). Foundational and instrumental design theory. Design /ssues, 27(4), 81-94. http://dx.doi.org/10.1162/ DESI a 00107

Harfield, S. (2007). On design 'problematization': Theorising differences in designed outcomes. Design Studies, 28(2), 159-173. http://dx.doi.org/10.1016/i.destud.2006.11.005

Hilpinen, R. (2011 [1999]). Artifacts. The Stanford Encyclopedia of Philosophy (Winter 2011 Edition). Retrieved from http:// plato.stanford.edu/archives/win2011/entries/artifact/

Houkes, W., \& Vermaas, P. E. (2010). Tecnnical Functions. On the Use and Design of Artefacts. Dordrecht: Springer.

Jones, E. S., \& Thiruvathukal, G. K. (2012). Codename Revolution. The Nintendo Wii Platform. Cambridge, MA: MIT Press.

Joost, G., \& Scheuermann, A. (Eds.). (2008). Design als Rhetorik. Basel: Birkhäuser Verlag.

Juul, J. (2010). A Casual Revolution: Reinventing Video Games and Their Players. Cambridge, MA: MIT Press.

Krippendorff, K. (2007). An exploration of artificiality. Artifact, 1(1), 17-22. http://dx.doi.org/10.1080/17493460600610848

Leff, M. (1997). The idea of rhetoric as interpretative practice: a humanist's response to Gaonkar. In A. Gross \& W. M. Keith (Eds.), Rhetorical hermeneutics: invention and interpretation in the age of science (pp. 89-100). Albany: State University of New York Press.

Norman, D. A. (2004). Emotional Design: Basic Books.

Rittel, H. (1972). On the planning crisis: systems analysis of the 'first and second generations'. Bedriftsøkonomen 8, 390-396.

Rittel, H., \& Webber, M. M. (1984 [1973]). Planning problems are wicked problems [Originally published 1973 as part of 'Dilemmas in a general theory of planning', Policy Sciences 4, pp 155-169]. In N. Cross (Ed.), Developments in design methodology (pp. 135-144). Chichester: John Wiley \& Sons.

Scheff, D. (1993). Game over: How nintendo zapped an american industry, captured your dollars, and enslaved your children. New York: Random House.

Schön, D. (1983). The reflective practitioner. How professionals think in action. New York: Basic Books.

Simon, H. A. (1996 [1969]). The Sciences of the artificial (3rd ed.). Cambridge, MA: MIT Press.

Stein, S. R. (2002). The "1984" Macintosh ad: Cinematic icons and constitutive rhetoric in the launch of a new machine. Quarterly Journal of Speech, 88(2), 169-192. http://dx.doi. org/10.1080/00335630209384369

Verganti, R. (2009). Design-driven innovation. Changing the rules of competition by radically innovating what things mean. Boston, MA: Harvard Business School Publishing. 


\section{CORRESPONDENCE}

Per L. Halstrøm

Copenhagen School of Design \& Technology; The

Royal Danish Academy of Fine Arts, School of

Design

Philip de Langes Allé 10

1435 Copenhagen $\mathrm{K}$

Denmark

E-mail: plha@kea.dk / peh@kadk.dk

Per Galle

The Royal Danish Academy of Fine Arts,

School of Design

Philip de Langes Allé 10

1435 Copenhagen K

Denmark

E-mail:pga@kadk.dk

Published online 28 July, 2015

ISSN 1749-3463 print/ISSN 1749-3471

http://dx.doi.org/10.14434/artifact.v3i4.12815

(C) 2015 Artifact

Copyright to illustrations in this article resides with the creator unless otherwise noted. Artifact publishes illustrations in accordance with commonly acknowledged fair use of visual materials for non-commercial research purposes. Creators who feel that publication is in violation of copyright or fair use should contact the editors. 